\title{
Cervical epidural steroid injections in the management of cervical radiculitis: interlaminar versus transforaminal. A review
}

\author{
Christopher W. Huston
}

Published online: 7 January 2009

(c) The Author(s) 2008. This article is published with open access at Springerlink.com

\begin{abstract}
There has been recent concern regarding the safety of cervical epidural steroid injections. The decision to proceed with treatment requires balancing the risk and benefits. This article is an in depth review of the efficacy, complications, and technique of both interlaminar and transforaminal cervical epidural steroid injections in the management of cervical radiculitis.
\end{abstract}

Keywords Cervical epidural steroid injections ·

Transforaminal · Interlaminar

\section{Introduction}

Cervical radiculitis affects approximately 83 per 100,000 population per year [1]. The most common causes of cervical radiculitis in this study were herniated disk in $21.9 \%$ and spondylosis in $68.4 \%$. The majority of those affected did not undergo surgery. Outcomes are favorable in both surgical and non-surgically treated groups without reproducible significant outcome differences of one treatment over the other [1-3]. The favorable outcome from cervical radiculitis from herniated disk may be due in part to the natural regression of disk herniation over time [4, 5]. However, well-designed randomized trials of surgical outcome and non-surgical outcome for specific diagnostic entities have not been performed. Current treatment strategies typically involve a gradual progression in the

C. W. Huston $(\bowtie)$

The Orthopedic Clinic Association, 2222 E. Highland Avenue, Suite 300, Phoenix, AZ 85016, USA

e-mail: cwhuston@cox.net aggressiveness of intervention, progressing from less to more invasive interventions only in refractory cases.

Initial treatment usually consists of activity modification, NSAID's, and physical therapy. Narcotic analgesics and analgesic adjuvants may be needed when pain is not adequately controlled. A cervical orthosis may provide comfort for some patients in the acute phase. If there is no improvement in 3-4 weeks of conservative treatment, cervical epidural steroid injections may be performed.

The rationale for corticosteroid instillation is the antiinflammatory affect. Cervical herniated disk specimens have demonstrated increased levels of matrix metalloproteinase activity, nitric oxide, prostaglandin E2, and interleukin-6 [6, 7]. Phospholipase A2 also plays a role in the inflammation of the nerve root and can be neurotoxic [8-10]. Epidural steroids have been shown to inhibit phospholipase A2 activity, thus reducing symptoms [10]. Corticosteroid mitigates nerve conduction slowing due to inflammation [11]. Corticosteroids also affect cell-mediated activity and cytokines, which may be involved in the pathogenesis of radicular pain [12].

Corticosteroids have actions other than anti-inflammatory. Corticosteroids stabilize nerve membranes inhibiting ectopic impulses [13], inhibits ion conductance [14], hyperpolarizes spinal neurons [15], and inhibits $\mathrm{C}$ fiber transmission [16]. These latter properties of corticosteroids can explain relief of symptoms in non-inflammatory states.

Local anesthetic mixed with the corticosteroid may have additional benefits beyond the direct anesthetic affects. Lidocaine has been shown to have anti-inflammatory effect on nucleus pulposus induced nerve injury [17]. Lidocaine has been demonstrated to increase intra-radicular blood flow in an animal compressed nerve root model [18]. This may improve intra-neural metabolism and reduce inflammatory mediators. 
The efficacy, complications, side-effects, and technique for interlaminar and transforaminal cervical epidural steroid injections are reviewed. Because of the paucity of studies, blinded interlaminar cervical epidural steroid injections are included in the review. However, the author does not condone the use of blinded interlaminar injections, which should become evident to the reader upon completion of this review.

\section{Efficacy}

Cervical epidural steroid injections (CESI) have been utilized for decades in the treatment of radicular pain. Over time the techniques in delivering corticosteroid into the epidural space has changed. Initial injections were performed blind-without fluoroscopy. Table 1 summarizes the following studies.

\section{Blind interlaminar CESI}

Rowlingson and Kirschenbaum [19] retrospectively present their results on 25 subjects with cervical radiculopathy who underwent 45 blind interlaminar CESI at C6-7 or C7-T1. Advanced imaging with $\mathrm{CT}$ and/or Myelography was performed in only 12 of the subjects. A compressive lesion was found in nine. Whether the compressive lesion correlated with the subject's symptoms was not stated. Average follow-up was 8.9 months. Excellent response defined as complete resolution of symptoms occurred in $24 \%$. Symptom improvement of greater than $75 \%$ occurred in $40 \%$. Three subjects had no improvement.

Mangar and Thomas [20] briefly report their results for 40 subjects who underwent 117 blind interlaminar CESI for cervical radiculitis. Greater than $70 \%$ pain relief and more than $50 \%$ relief were reported in $38 \%$ and $7 \%$, respectively. No relief occurred in $32 \%$. However, $75 \%$ of subjects with

Table 1 Summary of CESI outcomes. Under diagnosis, mixed indicates inclusion of subjects with neck pain only and neck and arm pain. Under type of CESI, blind refers to interlaminar injections performed without fluoroscopic guidance. TF indicates fluoroscopically guided transforaminal injection. IL indicates fluoroscopically guided interlaminar injection. See text for further descriptions of studies

\begin{tabular}{|c|c|c|c|c|c|c|}
\hline Investigators & Study design & $N$ & Diagnosis & CESI type & $\mathrm{F} / \mathrm{U}$ & Outcome \\
\hline $\begin{array}{l}\text { Rowlings and } \\
\text { Kirschenbaum }\end{array}$ & Retrospective & 25 & Non-specific & Blind & 8.9 months & $\begin{array}{l}24 \% \text { excellent } \\
40 \%>75 \% \text { relief }\end{array}$ \\
\hline Mangar and Thomas & Observational & 40 & HNP Spondylosis & Blind & Not stated & $\begin{array}{l}38 \%>70 \% \text { relief } \\
7 \%>50 \% \text { relief } \\
32 \% \text { no relief }\end{array}$ \\
\hline Ferrante & Retrospective & 100 & Mixed & Blind & 13.5 months & $62 \%$ with radiculitis with $>50 \%$ relief \\
\hline Stav & Randomized & 60 & Mixed & Blind & 1 year & $\begin{array}{l}>50 \% \text { decrease VAS } \\
\text { ESI: } 68 \% \\
\text { T.P. } 11.8 \%\end{array}$ \\
\hline Castagnera & Randomized & 24 & Chemical radiculitis & Blind & 3 months & $\begin{array}{l}\text { VAS } 87 \% \text { decrease } \\
\text { Steroid:lidocaine }=\text { Steroid:morphine }\end{array}$ \\
\hline Grenier & Prospective & 29 & Chemical radiculitis & Blind & 2 years & $83 \%$ Success \\
\hline Bush and Hillier & Prospective & 68 & HNP spondylosis & $\begin{array}{l}\text { Plexus TF } \\
\text { IL }\end{array}$ & 39 months & $\begin{array}{l}76 \% \text { Relief of arm pain } \\
84 \% \text { Full work capacity }\end{array}$ \\
\hline Bush & Prospective & 13 & HNP & Blind TF IL & 12 months & $\begin{array}{l}12 \text { Complete relief \& resolution of } \\
\text { HNP }\end{array}$ \\
\hline Vallee & Prospective & 32 & HNP spondylosis & $\mathrm{TF}$ & 6 months & $56 \%>50 \%$ relief \\
\hline Cyteval & Observational & 30 & HNP spondylosis & $\begin{array}{l}\text { TF-CT } \\
\text { guided }\end{array}$ & 6 months & $18 / 30$ VAS decreased from 6.3 to 0.7 \\
\hline Slipman & Retrospective & 22 & $\begin{array}{l}\text { Chemical radiculitis after } \\
\text { MVA }\end{array}$ & $\mathrm{TF}$ & 33.3 months & $\begin{array}{l}14 \% \text { Good to excellent } \\
\text { VAS: } 73.3 \text { to } 50.7\end{array}$ \\
\hline Slipman & Retrospective & 15 & Spondylosis with trauma & $\mathrm{TF}$ & 20.7 months & $20 \%$ Good to excellent \\
\hline Slipman & Retrospective & 20 & Spondylosis no trauma & $\mathrm{TF}$ & 21.2 months & $\begin{array}{l}60 \% \text { Good to excellent } \\
\text { VAS: } 6.9 \text { to } 2.0\end{array}$ \\
\hline Lin & Retrospective & 70 & HNP & $\mathrm{TF}$ & 13 months & $65.3 \%$ Good to excellent \\
\hline Anderberg & Randomized & 40 & Spondylosis & $\mathrm{TF}$ & 3 weeks & $\begin{array}{l}\text { Carbocaine with steroid vs. saline } \\
\text { No difference }\end{array}$ \\
\hline
\end{tabular}


herniated disk had improvement. Time from treatment to analysis was not reported in this retrospective review.

Ferrante et al. [21] retrospectively analyzed records of 100 subjects who underwent 235 blind midline interlaminar CESI for radicular or axial pain. Of those with radiculopathy, $62 \%$ had greater than or equal to $50 \%$ pain relief. Of those with cervical radiculitis with structural abnormality on imaging, only $35 \%$ had $50 \%$ or better pain relief.

Stav et al. [22] performed a prospective, randomized trial of blind interlaminar CESI (group A), posterior muscle trigger point with steroid:anesthetic mixture (group B), and intra-muscular lidocaine injection (group $\mathrm{C}$ ). Group $\mathrm{C}$ consisted of 10 subjects who were later divided equally into groups A and B. Groups A and B initially consisted of 25 subjects each, but 8 in group B were later excluded secondary to litigation. Inclusion was neck and neck with radicular pain from cervical disk disease or spondylosis that failed physical therapy and medications. Groups A and $B$ received 3 injections performed every 2 weeks. Outcome was considered very good for $75 \%$ decrease and good for $50-74 \%$ decrease in VAS. At 1 year, very good or good relief was $68 \%$ and $11.8 \%$ for groups $\mathrm{A}$ and $\mathrm{B}$, respectively. Group $C$ had poor results in all subjects at 3-4 week follow-up. The results suggest benefit from CESI.

The observational studies suggest a success rate of 40 $62 \%$ for blind, interlaminar CESI for cervical radiculopathy. The one prospective, randomized trial demonstrated superiority of blind, interlaminar CESI over trigger point injection for radicular pain. However, the actual diagnosis of subjects in these studies is elusive. Treatment outcomes will be dependent upon a specific diagnosis. Mangar and Thomas [20] support this premise noting $75 \%$ of subjects with a herniated disk had improvement, while overall success rate in their study was only $45 \%$.

For blind, interlaminar CESI only two studies were performed for a specific diagnostic group. Chemical radiculitis is defined as radicular pain in the absence of nerve root compression on imaging studies [23]. Castagnera et al. [24] randomized 24 subjects suffering from cervical chemical radiculitis treated with blind interlaminar CESI with steroid/lidocaine combination versus interlaminar CESI with steroid/morphine sulfate combination. At 3 months, there was no difference between groups with mean VAS decrease of $87 \%$ for both groups. The authors concluded there is no advantage to the addition of morphine to CESI. Grenier et al. [25] prospectively report on 29 subjects who underwent one blind interlaminar CESI at C7-T1 for chemical radiculitis with $83 \%$ success rate at 3 month follow-up that remained for 2 years.

Blind, interlaminar CESI may be misplaced $53 \%$ of the time utilizing the loss of resistance technique [26]. Hence, studies performed with blind, interlaminar CESI have been criticized for probably underestimating efficacy. Fluoroscopy with conformation utilizing non-ionic contrast agent has been advocated to improve accuracy of interlaminar CESI's [26].

Fluoroscopically guided interlaminar and transforaminal CESI

Bush and Hillier [27] prospectively evaluated with an independent review of 68 consecutive subjects suffering from cervical radiculopathy. Cervical spondylosis was present in $30 \%$ and herniated disk in $70 \%$ of subjects. Subjects received a cervical brachial plexus block. If no relief the subjects progressed to fluoroscopically guided transforaminal CESI and lastly, fluoroscopically guided interlaminar CESI. Twenty-nine percent had relief with brachial plexus injection, $62 \%$ with transforaminal CESI, and $16 \%$ interlaminar CESI. At mean follow-up of 39 months (range 4-112), 76\% had complete relief of arm pain and $24 \%$ had average pain score of 2 . Prior to treatment $75 \%$ had weakness. At follow-up $73 \%$ no longer experienced weakness. Eighty-four percent did not feel their symptoms interfered with their capacity to work.

Bush et al. [5] prospectively reported on 13 subjects with cervical radiculopathy from HNP that received either a blind injection, fluoroscopically guided transforaminal CESI or interlaminar CESI. An average follow-up of 12 months (range, 4-31 months) underwent telephone interview and repeat MRI. Twelve of thirteen had resolution of the herniated nucleus pulposus. The one subject with persistent herniated nucleus pulposus on MRI had residual neck pain.

While the above studies suggest CESI's are beneficial in the management of cervical radicular pain from a herniated disk, the lack of a control group does not exclude the improvement being secondary to the favorable natural history of cervical disk herniation. Saal et al. [28] experienced an $83 \%$ success rate for non-operative management of radiculopathy from a cervical disk herniation in 26 subjects. Treatment consisted of relative rest, modalities, hard cervical collar, medications, and physical therapy. Nine subjects with persistent symptoms underwent either fluoroscopically guided interlaminar or transforaminal CESI. Follow-up was over 1 year in all subjects.

Fluoroscopically guided transforaminal CESI

Fluoroscopy allowed the development of transforaminal CESI's. Transforaminal epidural injections have the advantage of being able to place medication directly around the dorsal root ganglion pathologically involved in causing a patient's radicular pain. Medication in the epidural space will tend to flow in the direction of least 
resistance. With interlaminar paramedian cervical epidural injections, the medication tends to spread unilateral in 51\% and ventral in only $28 \%$ [26]. The authors utilized a $2-\mathrm{ml}$ volume stating larger volumes could result in dilution of corticosteroid at the site of pathology. In a separate study with a midline approach, ventral flow occurred in $44.6 \%$ of epidural injections with volumes ranging from 2 to $4 \mathrm{ml}$ [29]. Foraminal and entrance zone disk herniations, cervical spondylotic foraminal stenosis, and epidural fibrosis can potentially block the flow of medication from an interlaminar epidural injection to the involved dorsal root ganglion. Hence, interventionalists seeking to improve efficacy began to perform transforaminal epidural steroid injections to put medication at the site of pathology.

Anderberg et al. [30] performed a prospective, randomized study of radicular pain from cervical spondylosis with positive MRI finding and $50 \%$ or greater relief with diagnostic selective nerve root injection. Subjects were randomized to receive either $0.5 \mathrm{ml}$ Carbocain and $1 \mathrm{ml}$ steroid (40 mg methylprednisolone) or $0.5 \mathrm{ml}$ Carbocain and $1 \mathrm{ml}$ saline transforaminal cervical epidural injection with fluoroscopic guidance. Follow-up was performed at 3 weeks. Twenty subjects were in each group with subjective improvement in pain occurred in 8 in the steroid group and 7 in the saline group. There was no statistical significance between groups.

Vallee et al. [31] prospectively evaluated transforaminal CESI performed on 32 consecutive subjects with radicular pain from foraminal stenosis either from spondylosis or disk herniation. At 6 months follow-up greater than 50\% relief occurred in $56 \%$ who also resumed full activities.

Cyteval et al. [32] report on 30 subjects with cervical radiculopathy from either spondylotic foraminal stenosis (16 subjects) or foraminal disk protrusion (14 subjects). All subjects had persistent symptoms despite 1 month of physical therapy and medication management. Subjects underwent one CT-guided transforaminal CESI. Eighteen subjects had good to excellent pain relief at 2 weeks with average VAS decreasing from 6.3 to 1.2. At 6 months these 18 subjects had mean VAS of 0.7 . For the 12 subjects with fair or poor results at 2 weeks, 3 had a second CT-guided transforaminal CESI. At 2 weeks from the second injection 2 subjects had greater than $75 \%$ relief (excellent) and 1 with less than $25 \%$ relief (poor).

Slipman et al. [33] retrospectively evaluated 22 subjects with radicular pain without a compressive lesion on imaging studies following a motor vehicle accident. All subjects had at least $80 \%$ pain reduction from a diagnostic cervical selective nerve root injection. Additionally, all subjects had greater arm than neck pain. Mean follow-up was 33.3 months (range 4-65 months). An average of 2.1 injections was performed. A steroid effect occurred in $59 \%$. Only $14 \%$ had a good to excellent outcome, based upon VAS, Oswestry, work status, and medication usage. Average Oswestry score at presentation and follow-up was 45.5 and 40.7, respectively. Average VAS score at presentation and follow-up was 73.3 and 50.7, respectively. However, high functioning at time of presentation had a more favorable outcome statistically with $48.9 \%$ improvement in pain and continued high functional status. The authors concluded transforaminal CESI was not indicated in this group except for possibly higher functioning individuals at presentation.

Slipman et al. [34] retrospectively report only $20 \%$ with good to excellent outcome with mean follow-up of 20.7 month for transforaminal CESI in 15 subjects for traumatically induced cervical spondylotic radicular pain. In these subjects with cervical spondylotic foraminal stenosis, symptoms occurred following a traumatic incident. Motor vehicle accident accounted for $46.7 \%$, fall $13.3 \%$, lifting injury $20 \%$, and sport injury $20 \%$. The authors concluded the use of transforaminal CESI is not supported in this group.

Slipman et al. [35] retrospectively present 20 subjects that underwent transforaminal CESI for radicular pain due to non-traumatic cervical spondylotic foraminal stenosis. Follow-up was done at an average of 21.2 months (range, 12-45 months) with subjects receiving an average of 2.2 injections. Sixty percent had good to excellent results. Pain decreased from VAS score 6.9 to verbal numeric scale score of 2.0. There was no significant change in employment status but significant decrease of medication usage.

Lin et al. [36] retrospectively reported on 70 consecutive subjects that underwent transforaminal CESI for radicular pain from a herniated cervical disk. All patients had been offered surgical treatment but given the option of a transforaminal CESI. Mean follow-up was 13 months (range, 6 months to 4 years) with $65.3 \%$ good to excellent relief with Odom criteria and avoidance of surgery. The authors found more favorable result in those over age 50 and symptom duration less than 100 days.

The above observational studies with cervical transforaminal ESI suggest benefit for radicular pain due to non-traumatic spondylotic stenosis and herniated disk [31, $35,36]$. However the lack of a control group does not exclude a favorable natural history. The studies also suggested transforaminal CESI is not beneficial in those with chemical radiculitis or cervical spondylotic foraminal stenosis following a motor vehicle accident $[33,34]$. The one randomized, prospective study was poorly designed [30]. A validated outcome measure was not utilized. For pain relief, any pain improvement at the 3 week follow-up was included. A subject with only $10 \%$ relief would be included in the same group as one with $90 \%$ relief. Only short-term outcome was measured. Also, local anesthetic has antiinflammatory effect and improves radicular flow both 
therapeutic benefits. Clinically, patients may receive from one to four therapeutic injections in a treatment regimen not just one. Nevertheless, prospective, randomized controlled trials are needed to determine the effectiveness of CESI in the management of radicular pain from herniated disk and spondylotic foraminal stenosis.

A randomized controlled trial of perineural injection was found to be superior to inter-laminar epidural injection in radiculitis from herniated lumbar disk [37]. A retrospective study also found lumbar transforaminal epidural steroid injections had superior pain reduction than interlaminar epidural steroid injections at short term and less surgical interventions at 1 year review [38]. These studies support the benefits of target-specific injection. However, studies of the lumbar spine cannot necessarily be extrapolated to the cervical spine. There are currently no prospective studies in the English literature comparing the effectiveness of transforaminal versus interlaminar CESI for specific diagnostic groups.

\section{Complications and side-effects}

The decision to proceed with any intervention not only requires understanding of the benefits but also the risks. Complications reported with interlaminar cervical epidural steroid injections include dural puncture, bloating, nausea and vomiting, vasovagal reaction, facial flushing, fever, nerve root injury, pneumocephalus, epidural hematoma, subdural hematoma, stiff neck, Cushing's syndrome, transient paresthesias, hypotension, respiratory insufficiency, transient blindness, epidural abscess, paralysis, cord injury, and death [39-51].

Complications reported with transforaminal cervical epidural steroid injections include neck pain, transient increased radicular pain, nausea, vasovagal reaction, dural puncture, non-specific headache, transient lightheadedness, dyspepsia, fluid retention, transient global amnesia, vertebral artery injury, paralysis, cord infarction and cerebellar infarction, and death [52-57].

\section{Blinded and fluoroscopically guided interlaminar CESI}

Waldman [58] prospectively reported upon complications with blind interlaminar C5-6 or C6-7 epidural steroid injections utilizing loss of resistance technique on 215 subjects receiving 790 injections. Complications were recorded immediately at 6 weeks by the pain management physician or nurse. Two individuals suffered dural puncture with headache requiring blood patching. There were 3 vasovagal reactions and one superficial infection.

Botwin et al. [59] retrospectively reported complications with fluoroscopically guided C6-7 or C7-T1 interlaminar epidural steroid injections on 157 subjects receiving 345 injections. Data were obtained at $24 \mathrm{~h}$ from the ambulatory surgical center questionnaire and 3 week physician followup. There was $6.7 \%$ neck pain, $4.6 \%$ non-positional headache, $1.7 \%$ insomnia, $1.7 \%$ vasovagal reaction, $1.5 \%$ facial flushing, $0.3 \%$ fever, and $0.3 \%$ dural puncture incidence. The overall rate of complications was $16.8 \%$.

\section{Fluoroscopically guided transforaminal CESI}

Ma et al. [52] reviewed records of 1,036 cervical transforaminal epidural steroid injections in 844 subjects. Immediate complications were recorded by the radiologist performing the procedure. If any complications occurred after discharge, the subjects were told to contact their referring physician. Hence, complications that occurred after discharge are at risk of being underreported. The authors' report complications occurred in 14 subjects $(1.66 \%)$. These included headache/dizziness $(0.59 \%)$, transient pain or weakness $(0.71 \%)$, hypersensitivity reaction $(0.12 \%)$, transient global amnesia $(0.12 \%)$, vasovagal reaction $(0.12 \%)$, and wrong site injection $(0.36 \%)$.

Huston et al. [53] performed a prospective, controlled study with independent interviewer of lumbar and cervical selective nerve root injections on 151 subjects who received 306 injections. The control group was 60 subjects with similar demographics and spinal complaints that did not undergo an intervention at time of interview. Procedural complications were recorded by the interventionalist. Immediate, 1 week and 3 month complications were recorded by an independent interviewer. Of the cervical group, there were 89 cervical selective nerve root injections performed on 37 subjects. There were no major complications. There was one dural puncture but the subject did not develop a headache and no treatment was needed. In the cervical group immediate complications were increased pain at injection site $22.7 \%$, increased radicular pain $18.2 \%$, lightheadedness $13.6 \%$, increased spine pain $9.1 \%$, non-specific headache $4.5 \%$, and nausea $3.4 \%$. One week follow-up compared to the control group had significance for increased pain at injection site $(P=.001)$, non-specific headache $(P=.019)$, and nonspinal headache $(P=.002)$. At 3 months follow-up 2 subjects complained of increased neck pain. One would repeat the injections again. The other subject would not repeat the injection. This subject did have complete resolution of radicular pain from a herniated disk but was not satisfied because of persistent neck pain.

Interlaminar versus transforaminal CESI

Incidence of dural puncture with interlaminar CESI ranges from $0.25 \%$ to $2.00 \%[21,58,60]$ and transforaminal CESI 
$1.12 \%$ [53]. With dural puncture the procedure is discontinued to avoid subarachnoid instillation of local anesthetic or corticosteroid. Instillation of local anesthesia could result in spinal anesthesia with respiratory depression, hypotension, and syncope [61]. Additionally, subarachnoid corticosteroid injection has been hypothesized to cause arachnoiditis [62, 63]. Celestone Chronodose has been evaluated in sheep and found to result in arachnoiditis at suprapharmacologic levels [64]. Epidural injections of triamcinolone and methyprednisolone in animal studies did not result in arachnoiditis or nerve root injury $[65,66]$.

After dural puncture, there is still the concern of spinal headache. However, dural puncture does not always result in a spinal headache [53, 58, 60, 61]. If a headache does occur, treatment may consist of strict bed rest, hydration, analgesics, and caffeine [67]. For severe or persistent headache interlaminar or transforaminal blood patching may be performed $[58,68]$.

The risk of dural puncture may be higher with an interlaminar than a transforaminal approach. Cryomicrotome studies of the cervical epidural space report absence of the posterior epidural space above C7-T1. In another study, the posterior epidural space at $\mathrm{C} 5$ has been reported at $1-1.5 \mathrm{~mm}$ [69]. Furthermore, there is an absence of the interspinous ligament in the cervical spine [69] along with half of specimens being deficient in the midline of the ligamentum flavum. Hence, blind injections utilizing loss of resistance technique may inadvertently puncture the dura. With transforaminal CESI, utilizing multi-planar imaging should avoid inadvertent dural puncture. On the AP view, the needle should not be advanced beyond the 6 o'clock (midline) position of the lateral mass. Dural puncture typically occurs by advancing the needle too far in the oblique plane. The technique section will discuss the need for frequent multi-planar imaging while advancing the spinal needle.

Non-positional headaches occurred with cervical selective nerve root injections in $4.5 \%$ and was found to be statistical significant when compared to a control population [53]. For fluoroscopically guided interlaminar CESI, non-positional headache occurred in $4.6 \%$. The rate is comparable between the two techniques. These headaches have been attributed to alterations in CSF pressure which is related to rapid injection and/or higher volumes [70, 71]. These headaches are typically transient and respond to oral analgesics. These headaches can be minimized by injecting slowly and the use of lower volumes.

Transient blindness after epidural steroid injection has been reported primarily with lumbar interlaminar and caudal injections. However, Kao [47] reported a case of impaired visual acuity following a C6-7 interlaminar ESI with $4 \mathrm{ml}$ lidocaine and $2 \mathrm{ml}$ triamcinolone. Five days after the second CESI, the patient developed headache, vomiting, neck stiffness, and decreased left visual acuity. A serous retinal detachment was found. The detachment resolved after 4 weeks but still with impaired vision. By 4 months, the patient reported normal vision. The cause of the retinal detachment is unknown. The author hypothesizes the following possibilities: (1) stress during the injection resulted in neuroendocrine alteration, (2) corticosteroid may have damaged the choroicapillaris with altered permeability, and (3) the corticosteroids may have elevated cathecholamine levels resulting in constriction of choroids vessels. If due to the steroids, then any utilization of corticosteroid whether oral, intra-muscular, or epidural with systemic absorption could potentially result in retinal detachment. Another possibility is increased CSF pressures which could explain the headache and vomiting the patient experienced. While the volume was $6 \mathrm{ml}$, rapid instillation could increase CSF pressures.

Bilateral retinal hemorrhages with transient blindness after caudal and lumbar ESI has been reported [72-75]. The retinal hemorrhages were felt to be related to increased CSF pressure created by rapid instillation and large volumes of medication injected with ESI [72,73]. Volumes of $20 \mathrm{ml}$ can increase CSF pressures [72]. Volumes of lidocaine and bupivicaine have ranged from 2 to $20 \mathrm{ml}$ with cervical interlaminar ESI [21, 58, 76]. Larger volume CESI's with rapid instillation should be avoided.

Cushing's syndrome has been reported after interlaminar CESI with $60 \mathrm{mg}$ of methylprednisolone [45]. The syndrome resolved after 12 months. Cushing's syndrome has also been reported after lumbar ESI. While Cushing's syndrome has not been reported with transforaminal ESI, the occurrence is probably related to the systemic absorption of the corticosteroid as opposed to the technique of delivery. Additionally, systemic affects of corticosteroids can result in hyperglycemia in diabetics and needs to be closely monitored.

Infection is always a risk whenever the skin is punctured. Huang et al. [51] present a case of epidural abscess following CESI. The patient initially presented with increased neck pain and chills. The patient subsequently developed left arm pain, paresthesia, and weakness but was neurologically intact in the lower extremities. An epidural abscess from $\mathrm{C} 4$ to $\mathrm{C} 6$ was seen on gadolinium-enhanced MRI. The patient underwent surgical decompression, irrigation, and debridement. The patient was placed on intravenous antibiotics. By 7 months post-operative, the patient regained baseline neurologic function [51]. Whether one technique is more predisposed is unknown. The procedure should be done with sterile technique. Additionally, the interventionalist should not touch the spinal needle tip. Both techniques are at risk for infection.

Nerve root injury and transient paresthesias have been reported after interlaminar CESI [46, 60]. After a blind 
interlaminar C5-6 ESI, nerve root injury was postulated as the initial injury resulting in complex regional pain syndrome [50]. For cervical selective nerve root injections transient increased radicular pain occurred in $18.2 \%$ but with no episodes of nerve root injury [53].

\section{Paralysis: interlaminar and transforaminal CESI}

Epidural hematoma after fluoroscopically guided C5-6 interlaminar CESI requiring surgical evacuation has been reported [42]. The patient had near full recovery of paralysis. Another case occurred within half and hour after painful paresthesia with the introduction to a Touhy needle at the C6-7 interspace [43]. The patient had incomplete recovery prior to surgery with high-dose intravenous methylprednisolone. The patient also required immediate surgical evacuation of the hematoma. Puncturing of the epidural venous plexus is the probable etiology. Whether the risk of epidural hematoma and subsequent quadriplegia is greater with interlaminar versus transforaminal CESI is unknown. However, with tranforaminal injections the needle is not placed directly into the spinal canal. Puncturing a radicular vein or artery within the foramen may be less likely to result in thrombosis formation with cord compression as the needle is not within the spinal canal. However, there may be other serious consequences of vascular puncture with transforaminal injections.

Brouwers [54] reported a case of tetraplegia following a right C6 transforaminal ESI with bupivicaine/triamcinolone mixture. The paralysis was consistent with anterior spinal artery syndrome. Another case was reported of cord infarction after left C6 transforaminal ESI with the patient suffering incomplete tetraplegia [56]. In another case, digital subtraction revealed puncture of a radicular artery terminating with several branches in the region of the spinal cord despite correct technique with a transforaminal cervical epidural injection [77]. The procedure was done with live fluoroscopy when injecting contrast. Fortunately, the procedure was abandoned without sequelae after noting the vascular flow. Tiso et al. [57] reported a case of cerebellar infarction after a C6 transforaminal CESI with bupivicaine/triamcinolone mixture. Intra-vascular injection of particulate steroid resulting in embolic occlusion through the vertebral artery with subsequent infarction was postulated as the cause. Pathology revealed bilateral cerebellar and occipital cortex infarction, thromboembolism of the leptomeningeal artery.

Light microscopy of steroid particulate size found up to $50 \mu \mathrm{m}$ particle size for methylprednisolone, triamcinolone, betamethasone sodium phosphate and acetate, dexamethasone, and betamethasone sodium phosphate [57]. Only betamethasone sodium phosphate had no particles greater than $50 \mu \mathrm{m}$. Less than $5 \%$ of particles were greater than
$50 \mu \mathrm{m}$ for methylprednisolone, betamethasone sodium phosphate and acetate, and dexamethasone. Methylprednisolone and triamcinolone had a tendency to coalesce into large aggregates of greater than $100 \mu \mathrm{m}$, which could result in sludging [57]. Particle and aggregate size is relevant when one considers the diameter of the artery system: artery $>50 \mu \mathrm{m}$, metarteriole $20-50 \mu \mathrm{m}$, arteriole 10 $15 \mu \mathrm{m}$, and capillary 5-8 $\mu \mathrm{m}$. Based upon dimensions, methylprednisolone and triamcinolone sludge could block smaller arteries and arterioles and result in ischemia [57]. Dexamethasone and betamethasone sodium phosphate would be better choices to avoid vascular occlusion. However, betamethasone sodium phosphate is not available commercially. While betamethasone sodium phosphate can be obtained through a compounding pharmacy, it is not recommended. Meningitis with subsequent death has been linked to compounding pharmacies making betamethasone sodium phosphate [78]. Hence, at this time, the corticosteroid recommended for transforaminal CESI is commercially available dexamethasone [57]. Furthermore, there was no statistical significance difference between outcomes with dexamethasone versus triamcinolone for cervical radicular pain [79].

Temporary paralysis was reported after a diagnostic C7 transforaminal injection with $0.8 \mathrm{ml} 2 \%$ lidocaine [80]. Sixty-seconds after injection the patient felt unwell. In the next 2-3 min the patient developed quadraparesis that resolved after $20 \mathrm{~min}$. The neurologic deficits were consistent with anterior spinal artery syndrome. The authors recommend injecting local anesthetic first and separate from the steroid [80].

The current hypothesis of tetraplegia following transforaminal epidural steroid injection relates to arterial injection of corticosteroid into a radiculomedullary artery with subsequent occlusion. The radiculomedullary arteries are major feeders to the anterior spinal artery. These arteries can arise anywhere from $\mathrm{C} 3$ to $\mathrm{C} 8$. Occlusion of a radiculomedullary artery can result in spinal cord infarction-anterior spinal artery syndrome. While vertebral artery puncture should be avoided by adhering to correct technique, Baker et al. [77] demonstrated a correct technique which can still result in injection into a radicular artery. When performing a transforaminal CESI, the following are modified recommendations to minimize the chance of radicular artery injection of corticosteroid [77]: (1) once the needle is in place, tubing should be connected to the spinal needle hub and syringe. This is to prevent inadvertent needle movement when attaching different syringes of injectate. (2) Injection of contrast under live fluoroscopy-evaluating for any vascular flow. Digital subtraction imaging may be of benefit. [3] If no vascular flow with contrast, then proceed to injection of local anesthetic under live fluoroscopy. The patient is then 
monitored for at least $90 \mathrm{~s}$. This is based upon the case report of Karasek and Bogduk [80] in which initial symptoms of radicular artery injection of local anesthetic occurred at $1 \mathrm{~min}$ and paralysis in $2 \mathrm{~min}$. After the time interval expires, the patient should be asked about a metallic taste, peri-oral numbness, auditory changes, agitation suggesting local anesthetic toxicity. Additionally pin-prick is tested in the hands and lower extremities along with movement of the hands and feet. If no signs are present to suggest anterior spinal artery syndrome or intraarterial injection, then proceed to step 4. (4) Before injecting dexamethasone, confirm needle placement has not changed utilizing fluoroscopy. Then slowly inject dexamethasone.

The occurrence of tetraplegia has opened the debate of whether transforaminal or interlaminar CESI should be performed. However, tetraplegia has occurred after interlaminar CESI. Cord injury following two cases of fluoroscopically guided interlaminar C5-6 ESI occurred in sedated patients [81]. The authors suggested the sedation did not allow the patients to respond to cord penetration by the needle. However, needle penetration of the cord in alert patients can be without pain or paresthesias [82]. While cord puncture may not be painful, injection of contrast agent into the cord produced pain [83]. Tetraplegia followed a fluoroscopically guided C6-7 interlaminar ESI [84]. While the cause is unknown, the authors hypothesized ischemic injury to the cord [84]. Bromage and Benumof reported a case of paralysis consistent with anterior artery syndrome in an individual undergoing spinal epidural anesthesia at T12 [85]. While the cause was unknown, the case report raised caution in epidural injections performed above the termination of the cord [85].

The cord is at risk of puncture with interlaminar CESI. The ligamentum flavum in the cervical region was found to be deficient in the midline in half of specimens [69]. Furthermore, the interspinous ligament is absent in the cervical spine [69]. When utilizing a loss of resistance technique, lack of resistance from absence of the interspinous ligament and unfused ligamentum flavum could lead to inadvertent dural and cord puncture. Performing the procedure under fluoroscopic guidance should help avoid inadvertent cord penetration.

Both interlaminar and transforaminal CESI's have case reports of catastrophic neurologic complications and death. The incidence of these complications while felt to be rare is unknown. Derby et al. [86] surveyed instructors of the International Spine Intervention Society. While not scientific, the survey revealed no major complication, no paralysis or death, in 4,389 interlaminar and 1,579 transforaminal injections. A national databank of complications would be helpful in determining the incidence of rare complications. This would be helpful in developing safer techniques and in appropriate consenting of patients undergoing CESI's. This system would be beneficial for the continuous improvement of patient care. Unfortunately, the current medical malpractice legal climate in the United States creates challenges in developing such a system.

\section{Technique}

Advanced imaging with magnetic resonance imaging (MRI) or at least multi-planar computed tomography should be obtained before proceeding with spinal interventions, including cervical epidural injections. Cervical spine MRI can determine the cause of radicular painherniated disk or cervical foraminal stenosis. If not diagnostic, further testing may be required-electrodiagnostic studies, diagnostic selective nerve root injections, brachial plexus MRI [87]. Knowing the cause of radicular pain will help determine the benefit of a cervical epidural injection. This is important in obtaining informed consent from the patient. Furthermore, one can plan the procedure noting any anatomic variances that may affect the procedure. The vertebral artery path can be followed to evaluate for a tortuous vertebral artery overlying a foramen that may interfere with a transforaminal injection. A tortuous vertebral artery in the $\mathrm{C} 4-5$ foramen compressing the $\mathrm{C} 5$ nerve root resulting in radicular symptoms has been reported [88]. Magnetic resonance angiogram (MRA) identified the tortuous artery [88]. Obviously, attempt at a transforaminal CESI in that case could have potentially resulted in cerebral vascular accident and death [55]. Central stenosis or posterior displacement of the cord reducing or obliterating the posterior epidural space at the level of a planned interlaminar cervical epidural injection places the cord at risk of puncture.

If a patient develops complications post-injection, a preprocedure MRI is very helpful to compare to a new MRI for any changes. Is the cystic structure seen on MRI a synovial cyst or abscess? Are the endplate changes Modic type I degenerative endplate changes or suggestions of osteomyelitis with marrow edema? A pre-procedure MRI would easily answer these questions.

\section{Anatomy}

Understanding cervical spine anatomy is imperative to the interventionalist performing cervical spine procedures. The epidural space is a triangular space extending from the foramen magnum to the sacral hiatus. The inner border is the thecal sac-dura mater. The outer border is the bony spinal canal and the covering periosteum. The anterior border is the posterior longitudinal ligament. The posterior border is the lamina and ligamentum flavum. The lateral 
border is the pedicle and intervertebral foramen. The epidural space contains loose areolar tissue, venous plexus, spinal nerve roots, radicular arteries, superficial and deep cervical arteries, arachnoid granules, and lymphatics. Above C7-T1 no posterior epidural space was evident on study [69]. The ligamentum flavum is unfused in the midline in approximately half of individuals and the interspinous ligament is absent [69].

Rootlets arise from the cord to form ventral and dorsal nerve roots which exit with the thecal sac covered with dura-the root sleeve. The dura ends at the proximal margin of the dorsal root ganglion. The ventral and dorsal roots coalesce to form the spinal nerve that exits from the foramen. The dura extends as the epiradicular sheath covering the dorsal root ganglion and spinal nerve. The spinal nerve is located in the inferior aspect of the foramen.

The foramen is formed by the superior and inferior pedicle. The superior articular process of the zygapophyseal joint forms the posterior wall. The anterior wall is superior vertebral endplate and disk.

The spinal nerve is posterior to the vertebral artery [89]. The vertebral artery arises from the subclavian and enters the costotransverse foramen at $\mathrm{C} 6$ and exits at $\mathrm{C} 1$ but can enter at C5 [90]. The vertebral artery crosses posterior to $\mathrm{C} 1 \mathrm{arch}$ before entering the skull through the foramen magnum. Branches from the vertebral artery descend forming the anterior spinal artery. The anterior spinal artery is divided into cervical, thoracic, and lumbar segments [89]. Spinal arteries arising from the vertebral, subclavian, and ascending cervical and deep cervical arteries enter through the foramen and divide into the anterior and posterior cervical radicular arteries [90]. Most radicular arteries supply the nerve root. A variable number of anterior radicular arteries supply the anterior spinal artery. These radicullomedullary arteries are larger and may ascend and descend within the thecal sac supplying the anterior spinal artery. In the cervical region a variable number of radicullomedullary arteries are present and may enter anywhere from C3 to C8 [91, 92] The radicular arteries and radicullomedullary arteries may be located posterior to the spinal nerve in the posterior-inferior aspect of the foramen, close to the target zone of transforaminal injections [90].

\section{Interlaminar CESI}

The patient is placed in a prone position on the fluoroscopy table with arms at the side. A blanket is placed under the chest. The neck is flexed with the head resting on a folded towel or blanket. To help prevent movement the head may be held in place with a Velcro strap though not all practitioners do this. The neck is prepped and draped in the usual sterile manner and sterile technique is utilized throughout the procedure. AP view is obtained to ensure the C7-T1 interspace located and the patient is correctly positioned in a true AP view. A skin wheal is raised with a 10:1 mixture of $1 \%$ lidocaine and $8.4 \%$ bicarbonate. A $20-22$ gauge Touhy needle is directed in the midline with a tunnel view parallel to the trajectory of the spinous processes. Once purchase of the needle in the paraspinal muscles occurs, a lateral view is obtained. A syringe containing normal saline is attached to the Touhy needle. Maintaining the same trajectory, the needle is advanced in the lateral plane checking for loss of resistance. The needle should not be advanced beyond the spinolaminar line. Advancing beyond this line risks dural and cord puncture. Additionally, loss of resistance may not occur despite entering the epidural space [93]. If the patient develops pain or paresthesias suggesting cord puncture or nerve root puncture, the needle should be withdrawn and the procedure abandoned. Contrast should not be injected as intra-cord instillation could be catastrophic [81]. More specifically, if cord puncture occurred, then dural puncture also occurred. Once loss of resistance occurs or the needle tip is at the spinolaminar line, needle advancement should stop. Position of the needle is checked in both the AP and lateral plane to ensure the needle is midline and at or only slightly beyond the spinolaminar line. A syringe contained non-ionic contrast (Isovue or Omnipaque) is attached to low volume extension tubing and flushed. Prior to attaching the extension tubing, a drop of contrast is placed in the Touhy needle to flush out any air. Then under live fluoroscopy contrast is injected evaluating for epidural flow and ensuring no vascular pattern. If a venous pattern occurs, the needle is withdrawn and repositioned. If an arterial pattern occurs, the procedure should be abandoned. If a myelographic pattern is obtained indicating subarachnoid injection, the procedure is abandoned [93]. Contrast should flow epidurally along the spinolaminar line creating a dorsal stripe [94]. Then under live fluoroscopy $2 \mathrm{cc}$ of $1 \%$ lidocaine and $2 \mathrm{cc}$ Dexamethasone is slowly infused. While the risk of radicular artery cannulation is probably lower for interlaminar injection, one may err on the side of caution and inject local anesthetic and steroid separately.

\section{Transforaminal CESI}

The patient is placed in the supine-oblique position on the fluoroscopy table. A towel or blanket is placed under the head to keep the neck parallel to the table. The patient is rolled into the correct position with the foramen perpendicular to the radiographic imager. A bolster is then placed behind the patient to support this position. The patient is prepped and draped in a sterile fashion and sterile technique is utilized throughout the procedure. Before starting, the interventionalist should review the image to visualize the target and path of the needle. One should visualize the path of the vertebral artery on the fluoroscopic image. If the 
patient's position is too oblique, the vertebral artery may be in the path of the needle. If too lateral, attempts to advance the needle into the foramen will result in anterior placement of the needle, risking vertebral artery puncture. Proper patient positioning is paramount. Once correctly positioned, a skin wheal is raised with 10:1 mixture of $1 \%$ lidocaine and $8.4 \%$ bicarbonate. A 22 gauge 1.5-2.5 inch spinal needle is advanced parallel to the radiographic beam to abut upon the mid-portion near the anterior edge of the superior articular process to gauge depth. The needle is slightly withdrawn and then redirected into the posterior aspect of the foramen 1-2 $\mathrm{mm}$. The position is checked in the AP plane, the needle tip should be slightly beyond the lateral border of the cervical pillar. The needle is then advanced $1-2 \mathrm{~mm}$ in the AP plane. If nerve is contacted, the patient typically experiences pain or paresthesia into the scapula or upper extremity. The needle should be slightly withdrawn off the nerve. The needle should not be advanced beyond the mid-sagittal line of the lateral mass. Oblique and lateral views are checked to ensure the needle is in the posterior aspect of the foramen [52]. A $1 \mathrm{cc}$ syringe containing non-ionic contrast (Isovue or Omnipaque) is connected to low volume extension tubing and flushed with contrast. The extension tubing is then connected to the spinal needle hub after first providing a drop of contrast into the spinal needle to flush out any air. The extension tubing minimizes the chance of needle movement with attaching and detaching the various syringes. Furthermore, the tubing keeps the interventionalist's hand away from the fluoroscopic beam. Contrast $0.5-1.0 \mathrm{cc}$ is then infused under live fluoroscopy carefully evaluating not only for outline of the nerve root but also for any vascular flow. If arterial flow is obtained the procedure is abandoned. If a myelographic pattern is obtained-dural puncture with subarachnoid injection - the procedure is abandoned. If venous flow is obtained, the needle is withdrawn back upon the superior articular process. The needle is then redirected into a different region of the foramen keeping the needle in the posterior half of the foramen-away from the vertebral artery. Multi-planar fluoroscopic imaging of needle placement is performed before infusion of contrast. Contrast should outline the nerve root with epidural flow and no vascular pattern. Digital subtraction imaging has been recommended but not required [77]. Preservative free $1 \%$ xylocaine $0.5-1.0 \mathrm{cc}$ is then instilled under live fluoroscopy carefully watching for any vascular flow. After $90 \mathrm{~s}$, the patient is queried about peri-oral numbness, metallic taste, tinnitus, light-headedness, shortness of breath, and agitation. The patient is asked to move the fingers and toes, and pin-prick is tested on the hands and lower legs or feet. If there are no untoward effects, $1.0-1.5 \mathrm{cc}$ dexamethasone may then be infused slowly. Before injecting, imaging is performed to ensure the needle position has not changed.
Sedation

Most patients do not require any sedation. For those who are very anxious, needle-phobic, vasovagal tendency, poor tolerance to pain or the procedure; intravenous minimal to moderate sedation may be performed. However, the patient still needs to be responsive to voice commands and have their protective mechanisms intact. More specifically, the patient should be able to respond with pain to needle touching nerve root or cord. As previously mentioned cord penetration may be asymptomatic. However, cord injection can be painful and the patient should be awake enough to respond to such an occurrence. The goal of moderate sedation is allow the patient to tolerate the procedure such that the procedure can be performed safely and without endangering the patient.

\section{Conclusion}

Cervical epidural steroid injections are frequently utilized in the treatment of cervical radicular pain. Pathophysiologic studies of cervical disk herniation support the utilization of corticosteroids. Observational studies are also supportive of cervical epidural injections in the management of cervical disk herniation and atraumatic cervical spondylotic foraminal stenosis. However, prospective, randomized controlled studies are needed. Transforaminal CESI's have been postulated to be more effective than interlaminar CESI's based upon accurate delivery of medication to the site of pathology. However, prospective studies are needed to compare the techniques. Both procedures have the potential for catastrophic complications. Whether one technique is safer than another is unknown. By utilizing impeccable technique complications can be minimized. Both procedures should be performed under fluoroscopy to reduce risk of serious complications and to ensure appropriate delivery of medication into the epidural space. The change to live fluoroscopy, separate injections of anesthetic and steroid, and the change to dexamethasone will hopefully minimize or eliminate the cases of anterior spinal artery syndrome following transforaminal CESI.

Open Access This article is distributed under the terms of the Creative Commons Attribution Noncommercial License which permits any noncommercial use, distribution, and reproduction in any medium, provided the original author(s) and source are credited.

\section{References}

1. Radhakrishnan K, Litchy WJ, O'Fallon WM, Kurland LT. Epidemiology of cervical radiculopathy: a population-based study of Rochester, Minnesota, 1976-1990. Brain. 1994;117:325-35. 
2. Sampath P, Bendebba M, Davis JD, Ducker T. Outcome in patients with cervical radiculopathy. Prospective, multicenter study with independent clinical review. Spine. 1999;24(6):591-7.

3. Heckmann JG, Lang CJG, Zobelein I, Laumer R, et al. Herniated cervical intervertebral discs with radiculopathy: an outcome study of conservatively or surgically treated patients. J Spinal Disord. 1999;12:396-401.

4. Maigne JY, Deligne L. Computed tomographic follow-up study of 21 cases of nonoperatively treated cervical intervertebral soft disc herniation. Spine. 1994;19:189-91.

5. Bush K, Chaudhuri R, Hillier S, Penny J. The pathomorphologic changes that accompany the resolution of cervical radiculopathy: a prospective study with repeat magnetic resonance imaging. Spine. 1997;22:183-6.

6. Kang JD, Georgescu LML, Stefanovic-Racic M, Evans CH. Herniated cervical intervertebral discs spontaneously produce matrix metalloproteinases, nitric oxide, interleukin-6, and prostaglandin E2. Spine. 1995;20:2373-8.

7. Furusawa N, Baba H, Miyoshi N, Maezawa Y, et al. Herniation of cervical intervertebral disc. Immunohistochemical examination and measurement of nitric oxide production. Spine. 2001;26: 1110-6.

8. Frans RC, saal JS, Saal JA. Human disc phopholipase A2 is inflammatory. Spine. 1992;17:S129-32.

9. Osaktay AC, Cavanaugh JM, Blagoev DC, King AI. Phospholipase A2 induced electrophysiologic and histologic changes in rabbit dorsal lumbar spine tissues. Spine. 1995;20:2659-68.

10. Lee HM, Weinstein JN, Meller ST, Hayashi N, et al. The role of steroids and their effects on phospholipase A2: an animal model of radiculopathy. Spine. 1998;23:1191-6.

11. Olmarker K, Byrod G, Cornefjord M, et al. Effects of methylprednisolone on nucleus pulposus-induced nerve root injury. Spine. 1994;19:1803-8.

12. Slipman CW, Huston CW, Shin C. Diagnostic and therapeutic injections. In: Gonzalez EG, Myers SJ, Edelstein JE, Lieberman JS, Downey JA, editors. Downey \& Darling's physiological basis of rehabilitation medicine. Boston: Butterworth Heinemann; 2001. p. 795-813.

13. Devor M, Govrin-Lippmann R, Raber P. Corticosteroids suppress ectopic neural discharge originating in experimental neuromas. Pain. 1985;22:127-37.

14. Hall ED. Glucocorticoid effect on central nervous excitability and synaptic transmission. Int Rev Neurobiol. 1982;23:165-95.

15. Hall ED. Acute effects of intravenous glucocorticoid on cat spinal motor neuron electrical properties. Brain Res. 1982;240:186-90.

16. Johansson A, Hao J, Sjolund B. Local corticosteroid application blocks transmission in normal nociceptive C-fibres. Acta Anaesthesiol Scand. 1990;34:335-8.

17. Shoji Y, Kawaguchi Y, Nordborg C, Kikuchi S, et al. Effects of lidocaine on nucleus pulposus-induced nerve root injury: a neurophysiologic and histologic study of the pig cauda equine. Spine. 1998;23:2383-9.

18. Yabuki S, Kikuchi S. Nerve root infiltration and sympathetic block. An experimental study of intraradicular blood flow. Spine. 1995;20:901-6.

19. Rowlingson JC, Kirschenbaum LP. Epidural analgesic techniques in the management of cervical pain. Anesth Analg. 1986;65:938-42.

20. Mangar D, Thomas PS. Epidural steroid injections in the treatment of cervical and lumbar pain syndromes. Reg Anesthesia. 1991;16:246.

21. Ferrante FM, Wilson SP, Iacobo C, Orav EJ, et al. Clinical classification as a predictor of therapeutic outcome after cervical epidural steroid injection. Spine. 1993;18:730-6.

22. Stav A, Ovadia L, Sternberg A, Kaadan M, et al. Cervical epidural steroid injection for cervicobrachialgia. Acta Anaesthesiol Scand. 1993;37:562-6.
23. Marshall LL, Trewhewie ER, Curtain CC. Chemical radiculitis. Clin Orthop Relat Res. 1977;129:68-71.

24. Castagnera L, Maurette P, Pointillart V, Vital JM, et al. Longterm results of cervical epidural steroid injection with and without morphine in chronic cervical radicular pain. Pain. 1994;58:239-43.

25. Grenier B, Castagnera L, Maurette P, Erny P, et al. Nevralgie cervico-brachiale chronique traitee par injection peridurale cervicale de corticoids. Resultants a long terme. Ann Fr Anesth Reanim. 1995;14:484-8.

26. Stojanovic MP, Vu TN, Caneris O, Slezak J, et al. The role of fluoroscopy in cervical epidural steroid injections: an analysis of contrast dispersal patterns. Spine. 2002;27:509-14.

27. Bush K, Hillier S. Outcome of cervical radiculopathy treated with periradicular/epidural corticosteroid injections: a prospective study with independent clinical review. Eur Spine J. 1996;5:319-25.

28. Saal JS, Saal JA, Yurth EF. Nonoperative management of herniated cervical intervertebral disc with radiculopathy. Spine. 1996;21:1877-83.

29. Goel A, Pollan J. Contrast flow characteristics in the cervical epidural space. An analysis of cervical epidurograms. Spine. 2006;31:1576-9.

30. Anderberg L, Annertz M, Persson L, Brandt L, et al. Transforaminal steroid injections for the treatment of cervical radiculopathy: a prospective and randomized study. Eur Spine J 2007;16:321-8.

31. Vallee JN, Feydy A, Carlier RY, Mutschler C, et al. Chronic cervical radiculpathy: lateral-approach periradicular corticosteroid injection. Radiology. 2001;218:886-92.

32. Cyteval C, Thomas E, Decoux E, Sarrabere MP, et al. Cervical radiculopathy: open study on percutaneous periradicular foraminal steroid infiltration performed under CT control in 30 patients. Am J Neuroradiol. 2004;25:441-5.

33. Slipman CW, Lipetz JS, Jackson HB, Plastaras CT, et al. Outcomes of therapeutic selective nerve root blocks for whiplash induced cervical radicular pain. Pain Physician. 2001;4:167-74.

34. Slipman CW, Lipetz JS, DePalma MJ, Jackson HB. Therapeutic selective nerve root block in the nonsurgical treatment of traumatically induced cervical spondylotic radicular pain. Am J Phys Med Rehabil. 2004;83:446-54.

35. Slipman CW, Lipetz JS, Jackson HB, Rogers DP, et al. Therapeutic selective nerve root block in the nonsurgical treatment of atraumatic cervical spondylotic radicular pain: a retrospective analysis with independent clinical review. Arch Phys Med Rehabil. 2000;81:741-6.

36. Lin EL, Lieu V, Halevi L, Shamie AN, et al. Cervical epidural steroid injections for symptomatic disc herniations. J Spinal Disord Tech. 2006;19:183-6.

37. Kraemer J, Ludwig J, Bickert U, et al. Lumbar epidural perineural injections: a new technique. Eur Spine J. 1997;6:357-61.

38. Schaufele MK, Hatch L, Jones W. Interlaminar versus transforaminal epidural injections for the treatment of symptomatic lumbar intervertebral disc herniations. Pain Physician. 2006;9:361-6.

39. Purkis IE. Cervical epidural steroids. Pain Clinic. 1986;1:3-7.

40. Simopoulos T, Peeters-Asdourian C. Pneumocephalus after cervical epidural steroid injection. Case report. Anesth Analg. 2001;92:1576-7.

41. Williams KN, Jackowski A, Evans PJD. Epidural haematoma requiring surgical decompression following repeated cervical epidural steroid injections for chronic pain. Pain. 1990;42:197-9.

42. Stoll A, Sanchez M. Epidural hematoma after epidural block: implication for its use in pain management. Surg Neurol. 2002; 57:235-40.

43. Ghaly RF. Recovery after high-dose methylprednisolone and delayed evacuation: a case of spinal epidural hematoma. J Neurosurg Anesthesiol. 2001;13:323-8. 
44. National Health and Medical Research Council. Epidural use of steroids in the management of back pain. Commonwealth of Australia 1994.

45. Tuel SM, Meythaler JM, Cross LL. Cushing's syndrome from epidural methylprednisolone. Pain. 1990;40:81-4.

46. Catchlove RFH, Braha R. Clinical reports: the use of cervical blocks in the management of chronic head and neck pain. Can Anaesth Soc J. 1984;31:188-91.

47. Kao LY. Bilateral serous retinal detachment resembling central seroud chorioretinopathy following epidural steroid injection. Retina. 1998;18:479-81.

48. Field J, Rathmell JP, Stephenson JH, Katz NP. Neuropathic pain following cervical epidural steroid injection. Anesthesiology. 2000;93:885-8.

49. Reitman CA, Watters W. Subdural hematoma after cervical epidural steroid injection. Spine. 2002;27:E174-6.

50. Siegfried RN. Development of complex regional pain syndrome after a cervical epidural steroid injection. Anesthesiology 1997; 86:1394-96.

51. Huang RC, Shapiro GS, Lim M, Sandhu HS, et al. Cervical epidural abscess after epidural steroid injection. Spine. 2003; 29:E7-9.

52. Ma DJ, Gilila LA, Riew KD. Complications of fluoroscopically guided extraforaminal cervical nerve blocks: an analysis of 1036 injections. J Bone Joint Surg. 2005;87-A:1025-30.

53. Huston CW, Slipman CW, Garvin C. Complications and side effect of cervical and lumbosacral selective nerve root injections. Arch Phys Med Rehabil. 2005;86:277-83.

54. Brouwers PJAM, Kottink EJBL, Dimone MAM, Prevo RL. A cervical anterior spinal artery syndrome after diagnostic blockade of the right C6-nerve root. Pain. 2001;91:397-9.

55. Rozin L, Rozin R, Koehler SA, et al. Death during transforaminal epidural steroid nerve root block(C7) due to perforation of the left vertebral artery. Am J Forensic Med Pathol. 2003;24:351-5.

56. Ludwig MA, Burns SP. Spinal cord infarction following cervical transforaminal epidural injection. Spine. 2005;30:E266-8.

57. Tiso RL, Cutler T, Catania JA, Whalen K. Adverse central nervous system sequelae after selective transforaminal block: the role of corticosteroids. Spine J. 2004;4:468-74.

58. Waldman SD. Complications of cervical epidural nerve blocks with steroids: a prospective study of 790 consecutive blocks. Reg Anesth. 1989;14:149-51.

59. Botwin KP, Gruber RD, Bouchlas CG, Torres-Ramos FM, et al. Complications of fluoroscopically guided transforaminal lumbar epidural injections. Arch Phys Med Rehabil. 2000;81:1045-50.

60. Cicala RS, Westbrook L, Angel JJ. Side effects and complications of cervical epidural steroid injections. J Pain Symptom Manage. 1989;4:64-6.

61. Jurmand SH. Corticotherapie peridurale des lombalgies et des sciatiques f'origine discale. EPU Rhum. 1972;24:5061-70.

62. Bernat JL. Intraspinal steroid therapy. Neurology. 1981;31:168-71.

63. Nelson DA. Dangers from methylprednisolone acetate therapy by intraspinal injection. Arch Neurol. 1988;45:804-6.

64. Latham JM, Fraser RD, Moore RJ, Blumbergs PC, et al. The pathologic effects of intrathecal betamethasone. Spine. 1997;22: 1558-62.

65. Cicala RS, Turner R, Moran E, Henley R, et al. Methylprednisolone acetate does not cause inflammatory changes in the epidural space. Anesthesiology. 1990;72:556-8.

66. Delaney TJ, Rowlingson JC, Carron H, Butler A. Epidural steroid effects on nerves and meninges. Anesth Analg. 1980;59:610-4.

67. Raskin NH. Lumbar puncture headache: a review. Headache. 1990;30:197-200.
68. Slipman CW, El Abd OH, Bhargava A, De Palma MJ, et al. Transforaminal cervical blood patch for the treatment of post-dural puncture headache. Am J Phys Med Rehabil. 2005;84:76-80.

69. Hogan QH. Epidural anatomy examined by cryomicrotome section. Reg Anesth. 1996;21:395-406.

70. Goebert HW, Jallo SJ, Wasmuth CE. Painful radiculopathy treated with epidural injections of procaine and hydrocortisone acetate: results in 113 patients. Anesth Analg. 1961;40:130-4.

71. Burn JMB, Langdon L. Lumbar epidural injections for the treatment of chronic sciatica. Rheumatol Phys Med. 1970;10:368-74.

72. Ling C, Atkinson PL, Munton CGF. Bilateral retinal haemorrhages following epidural injection. Br J Ophthalmol. 1993;77: 316-7.

73. Purdy EP, Ajimal GS. Vision loss after lumbar epidural steroid injection. Anesth Analg. 1998;86:119-22.

74. Kushner FH, Olson JC. Retinal hemorrhage as a consequence of epidural steroid injection. Arch Ophthalmol. 1995;113:309-13.

75. Young WF. Transient blindness after lumbar epidural steroid injection. A case report and literature review. Spine. 2002;27: E476-7.

76. Shulman M. Treatment of neck pain with cervical epidural steroid injection. Reg Anesth. 1986;11:92-4.

77. Baker R, Dreyfuss P, Mercer S, Bogduk N. Cervical transforaminal injection of corticosteroids into a radicular artery: a possible mechanism for spinal cord injury. Pain. 2003;103:211-5.

78. Traynor K. Meningitis deaths linked to drug shortage. ASHP News, July 17, 2001.

79. Dreyfuss P, Baker R, Bogduk N. Comparative effectiveness of cervical transforaminal injections with particulate and nonparticulate corticosteroid preparations for cervical radicular pain. Pain Med. 2006;7:237-42.

80. Karasek M, Bogduk N. Temporary neurologic deficit after cervical transforaminal injection of local anesthetic. Pain Med. 2004;5:202-5.

81. Hodges SD, Castleberg RL, Miller T, Ward R, et al. Cervical epidural steroid injection with intrinsic spinal cord damage: two case reports. Spine. 1998;23:2137-40.

82. Pounder D, Elliott S. An awake patient may not detect spinal cord puncture. Anaesthesia. 2000;55:194.

83. Servo A, Laasonen EM. Accidental introduction of contrast medium into the cervical spinal cord. A case report. Neuroradiology. 1985;27:80-2.

84. Bose B. Quariparesis following cervical epidural steroid injections: case report and review of the literature. Spine J. 2005;5: 558-63.

85. Bromage PR, Benumof JL. Paraplegia following intracord injection during attemped epidural anesthesia under general anesthesia. Reg Anesth Pain Med. 1998;23:104-7.

86. Derby R, Lee SH, Kim BJ, Chen Y, et al. Complications following cervical epidurals steroid injections by expert interventionalists in 2003. Pain Physician. 2004;7:445-9.

87. Huston CW, Slipman CW. Diagnostic selective nerve root blocks: indications and usefulness. Phys Med Rehabil Clin N Am. 2002;13:545-65.

88. Korinth MC, Mull M. Vetebral artery loop causing cervical radiculopathy. Surg Neurol. 2007;67:172-3.

89. Barr ML. Blood supply of the central nervous system. In: Barr ML, editor. The human nervous system. 3rd ed. Philadelphia: Harper Row; 1979. p. 293-303.

90. Huntoon MA. Anatomy of the cervical intervertebral foramina: vulnerable arteries and ischemic neurologic injuries after transforaminal epidural injections. Pain. 2005;117:104-11. 
91. Chakravorty BG. Arterial supply of the cervical spinal cord (with special reference to the radicular arteries). Anat Rec. 1971;170: 311-30.

92. Turnbull IM, Brieg A, Hassler O. Blood supply of cervical spinal cord in man. A microangiographic study. J Neurosurg. 1966;24: 951-65.
93. Derby R. Point of view: cervical epidural steroid injection with intrinsic spinal cord damage: two case reports. Spine. 1998;23:2141-2.

94. Lieberman R, Dreyfuss P, Baker R. Fluoroscopically guided interlaminar cervical epidural injections. Letter to the Editor. Arch Phys Med Rehabil. 2003;84:1568. 